\title{
Research on Evaluation on Agility of Agile Supply Chain Network Based on Complex Network Theory
}

\author{
Nai-Ru Xu ${ }^{1}$ and Jia-Bao Liu ${ }^{2}$ \\ ${ }^{1}$ The School of Finance and Economics, Anhui Wonder University of Information Engineering, Hefei 231201, China \\ ${ }^{2}$ The Department of Public Courses, Anhui Xinhua University, Hefei 230088, China \\ Correspondence should be addressed to Jia-Bao Liu; liujiabaoad@163.com
}

Received 19 August 2015; Revised 3 October 2015; Accepted 5 October 2015

Academic Editor: Young Hae Lee

Copyright (C) 2015 N.-R. Xu and J.-B. Liu. This is an open access article distributed under the Creative Commons Attribution License, which permits unrestricted use, distribution, and reproduction in any medium, provided the original work is properly cited.

\begin{abstract}
The paper tries to add the network structure factors of agile supply chain network into agility evaluation. The paper firstly presents three concepts including node strength centrality, betweenness centrality, and network centrality. They are used to calculate the weight of node enterprises in the agile supply chain network. And then, a series of agility indicators are designed to evaluate agility of agile supply chain network. AHP is used to calculate the weight of the indicators. Next, these indicators are used to get initial agility evaluation matrix by means of Delphi method, Data Mining, and so forth. Then FCE is used to calculate the membership degree on agility of node enterprises by combining the evaluation matrix with the weight of indicators. Last, the evaluation result of comprehensive agility of agile supply chain network is calculated on the basis of considering the weight of node enterprises. This method can reflect the effect which the network structure of supply chain network makes on the agility of the supply chain network. It is a complement to the current evaluation methods of agility.
\end{abstract}

\section{Introduction}

The progress of information technology and the development of globalization make the supply chain system more dynamic and complex. The supply chain system is a type of complex network consisting of the related entities. It includes many of suppliers, manufacturers, retailers, and customers. In the supply chain system, a new entity enters the system, which creates new connections between entities. Meanwhile, lots of interaction and interdependency relationships exist between different entities, progresses, and resources in the supply chain system. These interaction and interdependency relationships are highly nonlinear, multiscale, and complex. They cause interaction between the network structure and the function of the supply chain network, which leads to the evolution and the self-organization movement of the supply chain network [1].

From the view of complex network, the node represents business unit which can make decision independently; the link between nodes represents exchange relationship and underlined order. Thus, the complex network model can be constructed to mirror the supply chain system. The complex network model can reflect the characteristics of the efficient supply chain system $[2,3]$. This assumption has been realized and studied by some researchers [4-7].

The current changing market environment and dynamic evolution of business organization require that the supply network should become more agile so that the unpredicted market demand can be efficiently and effectively satisfied by means of dynamic, adaptive, separable network evolution and movement. Meanwhile, the unpredictable changes in the internal and external environment require that the supply chain system possesses the corresponding responsive ability [8]. However, the network structure decided by the way of organization and the approach of link between individual nodes, such as regular network, random network, and scalefree network, can affect the responsive speed and ability of the supply network, accordingly affecting the agility of the supply chain. In other words, the network structure affects the function and the behavior; at the same time, agility is a kind of attribute of the function and the behavior. Thus, the network structure is related to the agility closely. So, the research on 
the agility of the supply chain system must consider the state of network structure [9]. In the research literature on agility, there are two ways to follow: one way is to synthesize the evaluation results of agility of each individual node in the supply chain system to get the agility of the supply chain $[10,11]$. The defect of this way is that the evaluation result cannot reflect the effect which can be made by the whole network structure factors on the agility of the supply chain system. Another way is to view the supply chain system as an entirety and use a series of indicators assessing the entirety to evaluate the agility level in order to get the agility of the whole supply chain [12]. This approach seems to consider the comprehensiveness and wholeness but has great subjectivity. Because of lack of indicators which can accurately reflect the effect of the whole network structure, it is hard to get a scientific and reasonable evaluation result.

The paper adds the network structure factors into the agility evaluation of the supply chain system and meanwhile considers the types of node enterprises, the weight of node enterprises, and the weight of indicators and then obtains the comprehensive evaluation result finally. This method combines the analytic hierarchy process (AHP) with the fuzzy comprehensive evaluation (FCE) method based on incorporating the network structure factors into constructing a comprehensive evaluation method system in order to get the comprehensive agility evaluation result of the agile supply chain network.

\section{The Concept of Agility}

From the view of enterprise agility, the meaning of agility differs from the types of enterprises. The meaning of agility of the whole supply chain network is also different from the agility of single enterprise.

First, we give the definitions of agility of different types of node enterprises.

The agility of the node enterprise as a supplier is the ability of making response to sudden and unexpected changes [10].

The agility of the node enterprise as a manufacturer has two typical definitions. One definition is the ability of quick switching among different product models and production lines, which focuses on flexibility of production processes and procedures in order to respond to customer needs real-time and ideally [13]. Another definition is that enterprises quickly reconstruct the existing processes and explore new processes to follow after the demand trend in order to improve the ability of surviving in the highly dynamic competitive market environment [14].

The agility of the node enterprise as a distributor has two typical definitions. One definition is the surviving and development ability which can make response to quick changing and unexpected market by encouraging customers to engage in designing product and service in a competitive environment [15]. Another definition is the ability of providing low cost and high quality product with the short lead time and different quantity in order to create value for customers by customization [16].
Second, the definition of agility of the whole supply chain network is a kind of ability that the whole supply chain and its members rapidly form network alliance and carry out operations in order to deal with dynamic and volatile customer demand [17].

All the above definitions provide guides for designing different agility indicators for different types of node enterprises and the wholeness of the supply chain.

\section{Research Approach}

In the current research on agility evaluation of agile supply chain network, there are researches on the whole supply chain network and on the individual node enterprise. The paper deems that we should consider not only the network entirely and dynamically but also the position and influence of node enterprises in the agile supply chain network because the position and influence of node enterprises are different from each other. The agility influence of node enterprises is not the same in the whole supply chain network. So, the paper designs an agility evaluation model mixing with the influence of node enterprises on agile supply chain network. The research procedure includes four stages as follows.

First, use complex network theory to calculate three parameters in the agile supply chain network. They are node strength centrality, betweenness centrality, and network centrality. Then get the weight of individual node enterprises in agile supply chain network through processing these three parameters comprehensively.

Second, categorize the node enterprises into three basic types: suppliers, manufacturers, and distributors, and then design different evaluation indicators according to the types of node enterprises and use AHP to calculate the weight of indicators.

Third, use fuzzy comprehensive evaluation (FCE) to deal with the initial evaluation value of agility indicators which is produced by means of Delphi method, Data Mining, and so forth, and then use the weight of indicators to process the evaluation result.

Last, combine the agility evaluation result of node enterprises with the weight of node enterprises in order to calculate the comprehensive agility of the whole supply chain network. This method considers not only the agility of different types of node enterprises but also the effect which network structure makes on the agility. The schematic diagram of technology roadmap is as shown in Figure 1.

\section{The Procedure of Agility Evaluation}

4.1. The Definition of Three Parameters. Because different node enterprises have different network structure relationship, consequently, the node enterprises have importance and influence different from each other accordingly. The paper deploys the research road from each individual node to the whole network and obtains the influence level of node enterprise through analyzing the network structure relationship of the individual node. This kind of network 


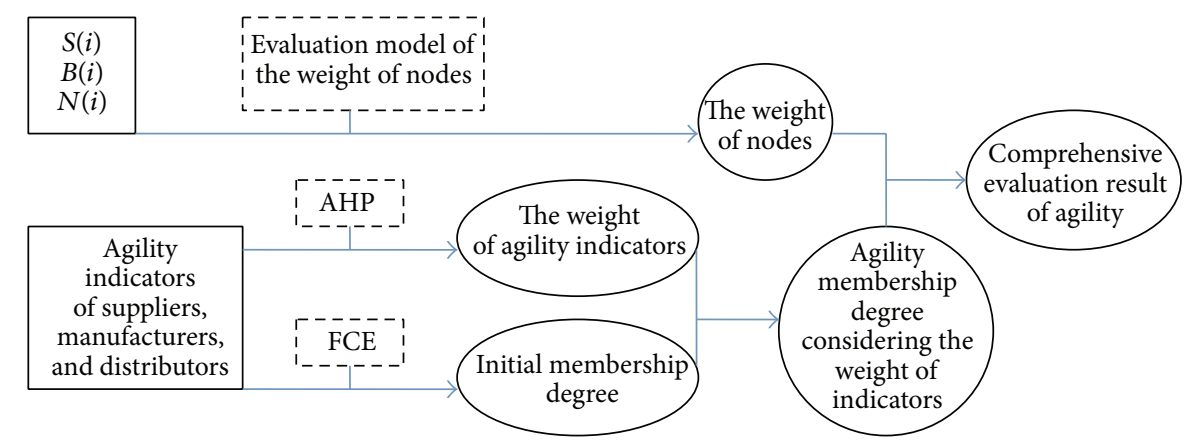

FIGURE 1: The schematic diagram of technology roadmap in the research. Note: the solid line rectangle represents indicators; the dotted line rectangle represents methods; the ellipse represents numerical value.

structure relationship is embodied in the following three parameters.

Three parameters of node enterprises in agile supply chain network are designed by means of complex network theory [18]. They are node strength centrality, betweenness centrality, and network centrality.

Definition 1 (node strength centrality, $S(i)$ ). Node strength centrality is that node strength of one node accounts for the proportion of the sum of node strength of all nodes. Node strength centrality can reflect the extent to which the responsive ability of one node can make a contribution to the responsive ability of the whole supply chain. The formula is as shown in

$$
S(i)=\frac{s_{i}}{\sum_{i=1}^{N} s_{i}},
$$

where $s_{i}=\sum_{j \in \Omega_{i}} a_{i j} w_{i j}$, where $w_{i j}$ means the weight of the edge $(i, j)$ and $a_{i j}$ is an adjacency matrix element; if node $v_{i}$ links to node $v_{j}, a_{i j}$ is 1 ; otherwise, $a_{i j}$ equals $0 . \Omega_{i}$ means the set of neighbor nodes of node $v_{i}$.

Definition 2 (betweenness centrality, $B(i)$ ). Betweenness centrality is that the number of shortest roads going through node $i$ accounts for the proportion of total number of shortest roads in the whole network, which represents the contribution which node $i$ makes to keep the network connective. The formula is as shown in

$$
B(i)=\sum_{x \neq y} \frac{a_{x y}(i)}{a_{x y}},
$$

where $a_{x y}$ means the number of all shortest roads between node $x$ and node $y$ in the whole network and $a_{x y}(i)$ means the number of the shortest roads between node $x$ and node $y$ which go through node $i$.

Definition 3 (network centrality, $N(i)$ ). Network centrality of node $i$ is a reciprocal of the sum of all distances from node $i$ to all other nodes, which represents position feature in the network; the bigger the number is, the closer node $i$ is to the network center; in other words, the influence of node $i$ is more obvious. The formula is as shown in

$$
N(i)=\frac{1}{\sum_{j=1}^{N} \beta_{i j}},
$$

where $\beta_{i j}$ means the number of edges being contained in the shortest path from node $i$ to node $j$ and $N$ means the total number of nodes in the network.

4.2. The Evaluation Model of the Weight of Node Enterprise. The basic idea of the model is to treat each node enterprise as a strategy and treat the indicators being used to evaluate enterprise influence as the properties of the strategy. The gap between the strategy of a certain enterprise and the best strategy or the worst strategy can reflect the influence level of the enterprise.

First, establish influence indicator matrix of node enterprises in agile supply chain network.

Suppose that there are $N$ enterprises in the agile supply chain network; the number of influence indicators is $s$, so we can create a set of strategies $U=\left\{U_{1}, \ldots, U_{N}\right\}$ and a set of indicators $V=\left\{V_{1}, \ldots, V_{S}\right\} . U_{i}\left(V_{j}\right)$ means influence indicator $j$ of enterprise $i$. Influence indicator matrix is as shown in

$$
G=\left[\begin{array}{ccc}
U_{1}\left(V_{1}\right) & \cdots & U_{1}\left(V_{s}\right) \\
\vdots & \ddots & \vdots \\
U_{n}\left(V_{1}\right) & \cdots & U_{n}\left(V_{s}\right)
\end{array}\right] .
$$

Because indicator dimensions are different from each other, they need to be standardized:

$$
u_{i j}=\frac{U_{i}\left(V_{j}\right)}{\sum_{i=1}^{N} U_{i}\left(V_{j}\right)} .
$$

After standardization, the influence indicator matrix is

$$
G^{*}=\left(u_{i j}\right)_{N * s} \text {. }
$$


Second, according to $G^{*}$, we get the best strategy indicator set $I^{+}$and the worst strategy indicator set $I^{-}$:

$$
\begin{aligned}
I^{+} & =\left\{\max \left(u_{11}, \ldots, u_{N 1}\right), \ldots, \max \left(u_{1 s}, \ldots, u_{N s}\right)\right\} \\
& =\left\{u_{1}^{\max }, \ldots, u_{s}^{\max }\right\} \\
I^{-} & =\left\{\min \left(u_{11}, \ldots, u_{N 1}\right), \ldots, \min \left(u_{1 s}, \ldots, u_{N s}\right)\right\} \\
& =\left\{u_{1}^{\min }, \ldots, u_{s}^{\min }\right\} .
\end{aligned}
$$

Third, calculate the gap between each strategy indicator and the best strategy indicator or the worst strategy indicator:

$$
\begin{aligned}
& M_{i}^{+}=\sum_{j=1}^{s}\left|u_{i j}-u_{j}^{\max }\right|, \\
& M_{i}^{-}=\sum_{j=1}^{s}\left|u_{i j}-u_{j}^{\min }\right| .
\end{aligned}
$$

Fourth, calculate proximity $T_{i}$ to the best strategy and use $T_{i}$ to measure the influence level of enterprise $i$ :

$$
T_{i}=\frac{M_{i}^{-}}{\left(M_{i}^{-}+M_{i}^{+}\right)} .
$$

The influence level of enterprise $i$ is proportional to proximity $T_{i}$.

Finally, we get the weight of the node enterprise $i$ :

$$
q_{i}=\frac{T_{i}}{\sum_{i=1}^{n} T_{i}} .
$$

4.3. The Comprehensive Agility Evaluation. Some of the influence factors on agility of supply chain network can be quantitatively evaluated directly and some of them cannot. Fuzzy comprehensive evaluation (FCE) is a combination of qualitative and quantitative features [19-21]. It can reflect the agility of various influence factors comprehensively. On the basis of comprehensive influence indicators evaluation of node enterprises, take enterprises influence indicators as parameters being used to build the model of evaluating agility of supply chain network.

According to fuzzy comprehensive evaluation theory, define $A_{i}=\left\{a_{i, 1}, a_{i, 2}, \ldots, a_{i, n}\right\}$ as a set of influence factor indicators of agility of node enterprise $i$.

Evaluation levels of all node enterprises are the same, which can be defined as $L=\left\{l_{1}, l_{2}, \ldots, l_{m}\right\}$. For each influence factor's indicators in $A_{i}$, a team of experts give fuzzy evaluation by means of a set of factor indicators and get evaluation matrix $(n \times m)$ of node enterprise $i$ :

$$
E_{i}=\left[\begin{array}{cccc}
e_{i, 11} & e_{i, 12} & \cdots & e_{i, 1 m} \\
e_{i, 21} & e_{i, 22} & \cdots & e_{i, 2 m} \\
\vdots & \vdots & \vdots & \vdots \\
e_{i, n 1} & e_{i, n 2} & \cdots & e_{i, n m}
\end{array}\right] .
$$

TABLE 1: The data of influence indicators of node enterprises in the agile supply chain network.

\begin{tabular}{lccc}
\hline ID & $S(i)$ & $B(i)$ & $N(i)$ \\
\hline 1 & 0.063333 & 0.000000 & 0.029412 \\
2 & 0.020000 & 0.000000 & 0.027778 \\
3 & 0.083333 & 0.000000 & 0.027778 \\
4 & 0.126667 & 0.469697 & 0.041667 \\
5 & 0.206667 & 0.515152 & 0.041667 \\
6 & 0.066667 & 0.303030 & 0.033333 \\
7 & 0.166667 & 0.530303 & 0.045455 \\
8 & 0.100000 & 0.151515 & 0.031250 \\
9 & 0.016667 & 0.000000 & 0.025000 \\
10 & 0.016667 & 0.000000 & 0.025000 \\
11 & 0.083333 & 0.000000 & 0.031250 \\
12 & 0.050000 & 0.000000 & 0.023810 \\
\hline
\end{tabular}

TABLE 2: The weight of node enterprises.

\begin{tabular}{lcccc}
\hline ID & $M_{i}^{+}$ & $M_{i}^{-}$ & $T_{i}$ & $P_{i}$ \\
\hline 1 & 0.45442 & 0.06127 & 0.11881 & 0.02982 \\
2 & 0.50201 & 0.01368 & 0.02652 & 0.00666 \\
3 & 0.43868 & 0.07701 & 0.14933 & 0.03748 \\
4 & 0.12065 & 0.39504 & 0.76604 & 0.19225 \\
5 & 0.01757 & 0.49812 & 0.96593 & 0.24242 \\
6 & 0.28700 & 0.22869 & 0.44346 & 0.11130 \\
7 & 0.04000 & 0.47569 & 0.92243 & 0.23150 \\
8 & 0.33603 & 0.17966 & 0.34839 & 0.08743 \\
9 & 0.51258 & 0.00311 & 0.00603 & 0.00151 \\
10 & 0.51258 & 0.00311 & 0.00603 & 0.00151 \\
11 & 0.42962 & 0.08607 & 0.16690 & 0.04189 \\
12 & 0.48236 & 0.03333 & 0.06463 & 0.01622 \\
\hline
\end{tabular}

There is the number of experts that deem that factor $a_{i, x}$ makes $l_{y}$ level effect on agility.

$e_{i, x y}$ is the ratio that the above experts account for the proportion of all experts in the team, which reflects membership degree of $a_{i, x}$ on $l_{y}$.

Meanwhile, the team grade the factor indicators and use AHP [22] to analyze the weight of factor indicators, forming a weight matrix $(1 \times n)$ of factor indicators on agility:

$$
F_{i}=\left[f_{i, 1}, f_{i, 2}, \ldots, f_{i, n}\right] .
$$

According to the evaluation matrix $E_{i}$ and the weight matrix $F_{i}$, we can obtain the evaluation result on agility of node enterprise $i$ :

$$
Z_{i}=F_{i} \cdot E_{i}
$$

The evaluation results of all node enterprises form evaluation matrix $(n \times m)$ of agility for agile supply chain network; the matrix is shown as $E^{*}$ :

$$
E^{*}=\left[Z_{1}, Z_{2}, \ldots, Z_{N}\right] .
$$


TABLE 3: Evaluation indicator system of agility in agile supply chain network.

\begin{tabular}{|c|c|c|}
\hline The type of node & The 1st-class indicator & The 2nd-class indicator \\
\hline \multirow{10}{*}{ Supplier $(S)$} & \multirow{4}{*}{ Customer response capacity (A1) } & The rate of timely transmission of information (A11) \\
\hline & & $\begin{array}{l}\text { The rate of accurate transmission of information } \\
\text { (A12) }\end{array}$ \\
\hline & & The rate of delivery on time (A13) \\
\hline & & Delivery period (A14) \\
\hline & \multirow{3}{*}{$\begin{array}{l}\text { Logistics operation capacity [23] } \\
\text { (A2) }\end{array}$} & Order processing speed (A21) \\
\hline & & Dispatching speed (A22) \\
\hline & & The speed of delivery (A23) \\
\hline & \multirow{3}{*}{ Supply capacity (A3) } & The rate of order-fulfilling (A31) \\
\hline & & The rate of delivery on time (A32) \\
\hline & & Inventory level (A33) \\
\hline \multirow{10}{*}{ Manufacturer $(M)$} & \multirow{3}{*}{ Production flexibility (B1) } & The ability of scalability (B11) \\
\hline & & Process reengineering $(\mathrm{B} 12)$ \\
\hline & & Multiple employee skills (B13) \\
\hline & \multirow{3}{*}{ Cooperation capacity (B2) } & Resource sharing (B21) \\
\hline & & The level of resource integration (B22) \\
\hline & & Information sharing (B23) \\
\hline & \multirow{4}{*}{ Market response capacity (B3) } & $\begin{array}{l}\text { The rate of accurate transmission of information } \\
\text { (B31) }\end{array}$ \\
\hline & & The rate of timely transmission of information (B32) \\
\hline & & Delivery period (B33) \\
\hline & & The rate of delivery on time (B34) \\
\hline \multirow{10}{*}{ Distributor $(D)$} & \multirow{4}{*}{ Market response capacity $(\mathrm{C} 1)$} & The rate of timely transmission of information (C11) \\
\hline & & $\begin{array}{l}\text { The rate of accurate transmission of information } \\
(\mathrm{C} 12)\end{array}$ \\
\hline & & The rate of delivery on time (C13) \\
\hline & & Delivery period (C14) \\
\hline & \multirow{3}{*}{ Logistics operation capacity (C2) } & Order processing speed (C21) \\
\hline & & Dispatching speed (C22) \\
\hline & & The speed of delivery (C23) \\
\hline & \multirow{3}{*}{ The level of service quality (C3) } & The rate of product satisfaction $(\mathrm{C} 31)$ \\
\hline & & The rate of customer complaint (C32) \\
\hline & & The rate of solved customer complaint (C33) \\
\hline
\end{tabular}

TABLE 4: The calculation example of indicator weight based on AHP.

\begin{tabular}{lccccccc}
\hline A1 & A11 & A12 & A13 & A14 & $\overline{W_{i}}$ & $W_{i}$ & $\lambda_{\max }=4.065$ \\
A11 & 1 & 3 & 5 & 3 & 2.590 & 0.529 & CI $=0.022$ \\
A12 & $1 / 3$ & 1 & 2 & $1 / 2$ & 0.760 & 0.155 & RI $=0.90$ \\
A13 & $1 / 5$ & $1 / 2$ & 1 & $1 / 2$ & 0.470 & 0.097 & CR $=0.024<0.1$ \\
A14 & $1 / 3$ & 2 & 2 & 1 & 1.075 & 0.219 & \\
\hline
\end{tabular}

According to formula (10), we can calculate the weight coefficient, (11), and get enterprise weight matrix $Q^{*}$ :

$$
Q^{*}=\left[q_{1}, q_{2}, \ldots, q_{n}\right] \text {. }
$$

At last, we obtain the comprehensive agility evaluation result of agile supply chain network:

$$
Z^{*}=Q^{*} \cdot E^{*} \text {. }
$$

\section{Case Analysis}

There is an agile supply chain network including three suppliers of the first class, two suppliers of the second class, three manufacturers, and four distributors. The network structure of agile supply chain is shown as Figure 2.

Step 1. Use formulas (1), (2), and (3) to calculate node strength centrality $S(i)$, betweenness centrality $B(i)$, and 


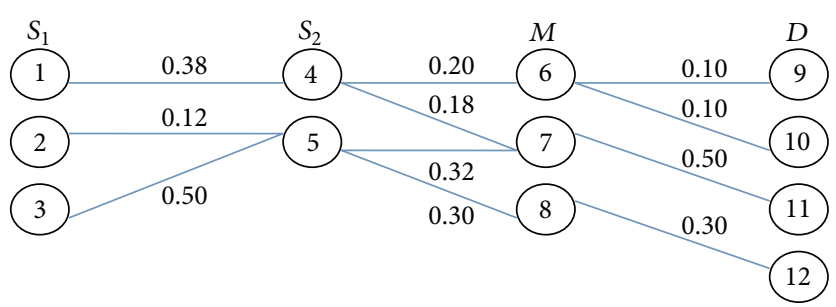

FIGURE 2: The structure diagram of the agile supply chain network. Note: $S_{1}$ means the supplier of the 1st class, $S_{2}$ means the supplier of the 2nd class, $M$ means manufacturer, $D$ means distributor, and the edge weight means the responsive ability between node enterprises; the responsive ability comes from a comparison between the same type of enterprises; there is no comparison between different types of enterprises.

network centrality $N(i)$ of node enterprises, as shown in Table 1.

The data in Table 1 can be processed by unifying indicator dimensions; then get unified dimensional influence indicator matrix $G^{*}$ :

$$
G^{*}=\left[\begin{array}{lll}
0.06333 & 0.00000 & 0.07671 \\
0.02000 & 0.00000 & 0.07245 \\
0.08333 & 0.00000 & 0.07245 \\
0.12667 & 0.23846 & 0.10868 \\
0.20667 & 0.26154 & 0.10868 \\
0.06667 & 0.15385 & 0.08694 \\
0.16667 & 0.26923 & 0.11856 \\
0.10000 & 0.07692 & 0.08151 \\
0.01667 & 0.00000 & 0.06521 \\
0.01667 & 0.00000 & 0.06521 \\
0.08333 & 0.00000 & 0.08151 \\
0.05000 & 0.00000 & 0.06210
\end{array}\right] .
$$

According to the standardized matrix $G^{*}$, we can use the best strategy indicator set $I^{+}$, (7), and the worst strategy indicator set $I^{-},(8)$, to calculate the gap between each strategy and the best strategy or the worst strategy:

$$
\begin{aligned}
& I^{+}=\left\{\begin{array}{lll}
0.20667 & 0.26923 & 0.11856
\end{array}\right\}, \\
& I^{-}=\left\{\begin{array}{lll}
0.01667 & 0.00000 & 0.06210
\end{array}\right\} .
\end{aligned}
$$

Then calculate proximity $T_{i}(10)$ to the best strategy; finally calculate the weight of each node enterprise, as shown in Table 2.

Step 2. Design evaluation indicator system of agility of supply chain network and use AHP to calculate the weight of indicators. The indicator system is as shown in Table 3.

Use AHP to calculate the indicator weight; the example of calculation is shown as in Table 4 .

The calculation result of all indicators is shown as in Table 5.

Step 3. Calculate the membership degree of the indicator

\begin{tabular}{|c|c|c|c|c|}
\hline $\begin{array}{l}\text { The type } \\
\text { of node }\end{array}$ & $\begin{array}{l}\text { The 1st-class } \\
\text { indicator }\end{array}$ & Weight & $\begin{array}{l}\text { The 2nd-class } \\
\text { indicator }\end{array}$ & Weight \\
\hline \multirow{10}{*}{$S$} & \multirow{4}{*}{$\mathrm{A} 1$} & \multirow{4}{*}{0.391} & A11 & 0.529 \\
\hline & & & A12 & 0.155 \\
\hline & & & $\mathrm{A} 13$ & 0.097 \\
\hline & & & A14 & 0.219 \\
\hline & \multirow{3}{*}{ A2 } & \multirow{3}{*}{0.308} & A21 & 0.296 \\
\hline & & & A22 & 0.265 \\
\hline & & & A23 & 0.440 \\
\hline & \multirow{3}{*}{ A3 } & \multirow{3}{*}{0.302} & A31 & 0.347 \\
\hline & & & A32 & 0.329 \\
\hline & & & A33 & 0.324 \\
\hline \multirow{10}{*}{$M$} & \multirow{3}{*}{ B1 } & \multirow{3}{*}{0.374} & B11 & 0.347 \\
\hline & & & B12 & 0.329 \\
\hline & & & B13 & 0.324 \\
\hline & \multirow{3}{*}{ B2 } & \multirow{3}{*}{0.359} & B21 & 0.233 \\
\hline & & & B22 & 0.467 \\
\hline & & & B23 & 0.300 \\
\hline & \multirow{4}{*}{ B3 } & \multirow{4}{*}{0.267} & B31 & 0.229 \\
\hline & & & B32 & 0.287 \\
\hline & & & B33 & 0.268 \\
\hline & & & B34 & 0.216 \\
\hline \multirow{10}{*}{$D$} & \multirow{4}{*}{$\mathrm{Cl}$} & \multirow{4}{*}{0.360} & C11 & 0.270 \\
\hline & & & $\mathrm{C} 12$ & 0.330 \\
\hline & & & $\mathrm{C} 13$ & 0.201 \\
\hline & & & C14 & 0.199 \\
\hline & \multirow{3}{*}{ C2 } & \multirow{3}{*}{0.265} & C21 & 0.296 \\
\hline & & & C22 & 0.265 \\
\hline & & & $\mathrm{C} 23$ & 0.440 \\
\hline & \multirow{3}{*}{ C3 } & \multirow{3}{*}{0.375} & C31 & 0.328 \\
\hline & & & C32 & 0.342 \\
\hline & & & C33 & 0.330 \\
\hline
\end{tabular}
evaluation grade.
TABLE 5: The calculation result of indicator weight.

Use a series of methods such as Delphi method and Data Mining to get initial membership degree of the 2nd-class indicators of suppliers, manufacturers, and distributors, as shown in Tables 6-8. 
TABLE 6: The membership degree of evaluation grade of the 2nd-class indicators on suppliers.

\begin{tabular}{|c|c|c|c|c|c|c|c|c|c|c|c|}
\hline \multirow{2}{*}{ Node } & \multirow{2}{*}{ Grade } & \multicolumn{10}{|c|}{ Indicator } \\
\hline & & A11 & A12 & A13 & A14 & A 21 & A22 & A23 & A31 & A32 & A33 \\
\hline \multirow{4}{*}{1} & A & 0.0 & 0.0 & 0.2 & 0.1 & 0.0 & 0.0 & 0.2 & 0.1 & 0.3 & 0.2 \\
\hline & B & 0.6 & 0.6 & 0.4 & 0.5 & 0.4 & 0.5 & 0.4 & 0.6 & 0.6 & 0.5 \\
\hline & $\mathrm{C}$ & 0.4 & 0.4 & 0.4 & 0.4 & 0.6 & 0.5 & 0.4 & 0.3 & 0.1 & 0.3 \\
\hline & $\mathrm{D}$ & 0.0 & 0.0 & 0.0 & 0.0 & 0.0 & 0.0 & 0.0 & 0.0 & 0.0 & 0.0 \\
\hline \multirow{4}{*}{2} & A & 0.1 & 0.1 & 0.2 & 0.0 & 0.0 & 0.0 & 0.2 & 0.1 & 0.2 & 0.2 \\
\hline & B & 0.7 & 0.7 & 0.4 & 0.5 & 0.4 & 0.6 & 0.5 & 0.6 & 0.6 & 0.6 \\
\hline & $\mathrm{C}$ & 0.2 & 0.2 & 0.4 & 0.5 & 0.6 & 0.4 & 0.3 & 0.3 & 0.2 & 0.2 \\
\hline & $\mathrm{D}$ & 0.0 & 0.0 & 0.0 & 0.0 & 0.0 & 0.0 & 0.0 & 0.0 & 0.0 & 0.0 \\
\hline \multirow{4}{*}{3} & A & 0.0 & 0.1 & 0.2 & 0.1 & 0.2 & 0.2 & 0.2 & 0.2 & 0.1 & 0.2 \\
\hline & B & 0.6 & 0.6 & 0.4 & 0.5 & 0.4 & 0.5 & 0.4 & 0.6 & 0.6 & 0.5 \\
\hline & $\mathrm{C}$ & 0.4 & 0.3 & 0.4 & 0.4 & 0.4 & 0.3 & 0.4 & 0.2 & 0.3 & 0.3 \\
\hline & $\mathrm{D}$ & 0.0 & 0.0 & 0.0 & 0.0 & 0.0 & 0.0 & 0.0 & 0.0 & 0.0 & 0.0 \\
\hline \multirow{4}{*}{4} & A & 0.1 & 0.1 & 0.2 & 0.0 & 0.1 & 0.0 & 0.2 & 0.1 & 0.2 & 0.2 \\
\hline & B & 0.6 & 0.6 & 0.6 & 0.7 & 0.7 & 0.6 & 0.6 & 0.6 & 0.6 & 0.6 \\
\hline & C & 0.3 & 0.3 & 0.2 & 0.3 & 0.2 & 0.4 & 0.2 & 0.3 & 0.2 & 0.2 \\
\hline & $\mathrm{D}$ & 0.0 & 0.0 & 0.0 & 0.0 & 0.0 & 0.0 & 0.0 & 0.0 & 0.0 & 0.0 \\
\hline \multirow{4}{*}{5} & A & 0.1 & 0.1 & 0.0 & 0.0 & 0.0 & 0.0 & 0.1 & 0.1 & 0.2 & 0.2 \\
\hline & B & 0.6 & 0.6 & 0.7 & 0.7 & 0.6 & 0.6 & 0.6 & 0.6 & 0.6 & 0.6 \\
\hline & $\mathrm{C}$ & 0.3 & 0.3 & 0.3 & 0.3 & 0.4 & 0.4 & 0.3 & 0.3 & 0.2 & 0.2 \\
\hline & $\mathrm{D}$ & 0.0 & 0.0 & 0.0 & 0.0 & 0.0 & 0.0 & 0.0 & 0.0 & 0.0 & 0.0 \\
\hline
\end{tabular}

Note: A: excellent, B: good, C: average, and D: poor.

TABLE 7: The membership degree of evaluation grade of the 2nd-class indicators on manufacturers.

\begin{tabular}{|c|c|c|c|c|c|c|c|c|c|c|c|}
\hline \multirow{2}{*}{ Node } & \multirow{2}{*}{ Grade } & \multicolumn{10}{|c|}{ Indicator } \\
\hline & & B11 & B12 & B13 & B21 & B22 & $\mathrm{B} 23$ & B31 & B32 & B33 & B34 \\
\hline \multirow{4}{*}{6} & A & 0.1 & 0.1 & 0.0 & 0.2 & 0.2 & 0.0 & 0.0 & 0.0 & 0.1 & 0.1 \\
\hline & B & 0.6 & 0.6 & 0.6 & 0.6 & 0.6 & 0.7 & 0.6 & 0.6 & 0.5 & 0.5 \\
\hline & $\mathrm{C}$ & 0.3 & 0.3 & 0.4 & 0.2 & 0.2 & 0.2 & 0.4 & 0.4 & 0.4 & 0.4 \\
\hline & $\mathrm{D}$ & 0.0 & 0.0 & 0.0 & 0.0 & 0.0 & 0.1 & 0.0 & 0.0 & 0.0 & 0.0 \\
\hline \multirow{4}{*}{7} & A & 0.1 & 0.1 & 0.0 & 0.1 & 0.1 & 0.0 & 0.0 & 0.0 & 0.1 & 0.1 \\
\hline & B & 0.7 & 0.7 & 0.7 & 0.6 & 0.6 & 0.6 & 0.6 & 0.6 & 0.5 & 0.5 \\
\hline & C & 0.2 & 0.2 & 0.3 & 0.3 & 0.3 & 0.3 & 0.4 & 0.4 & 0.4 & 0.4 \\
\hline & $\mathrm{D}$ & 0.0 & 0.0 & 0.0 & 0.0 & 0.0 & 0.1 & 0.0 & 0.0 & 0.0 & 0.0 \\
\hline \multirow{4}{*}{8} & $\mathrm{~A}$ & 0.1 & 0.1 & 0.0 & 0.1 & 0.1 & 0.0 & 0.0 & 0.0 & 0.1 & 0.1 \\
\hline & B & 0.6 & 0.7 & 0.6 & 0.6 & 0.6 & 0.7 & 0.6 & 0.7 & 0.6 & 0.6 \\
\hline & C & 0.3 & 0.2 & 0.4 & 0.3 & 0.3 & 0.2 & 0.4 & 0.3 & 0.3 & 0.3 \\
\hline & $\mathrm{D}$ & 0.0 & 0.0 & 0.0 & 0.0 & 0.0 & 0.1 & 0.0 & 0.0 & 0.0 & 0.0 \\
\hline
\end{tabular}

Note: A: excellent, B: good, C: average, and D: poor. 
TABLE 8: The membership degree of evaluation grade of the 2nd-class indicators on distributors.

\begin{tabular}{|c|c|c|c|c|c|c|c|c|c|c|c|}
\hline \multirow{2}{*}{ Node } & \multirow{2}{*}{ Grade } & \multicolumn{10}{|c|}{ Indicator } \\
\hline & & C11 & $\mathrm{C} 12$ & $\mathrm{C} 13$ & $\mathrm{C} 14$ & $\mathrm{C} 21$ & $\mathrm{C} 22$ & $\mathrm{C} 23$ & C31 & C32 & C33 \\
\hline \multirow{4}{*}{9} & A & 0.2 & 0.2 & 0.2 & 0.1 & 0.1 & 0.2 & 0.2 & 0.7 & 0.4 & 0.6 \\
\hline & B & 0.6 & 0.6 & 0.5 & 0.6 & 0.7 & 0.6 & 0.7 & 0.3 & 0.4 & 0.3 \\
\hline & $\mathrm{C}$ & 0.2 & 0.2 & 0.3 & 0.3 & 0.2 & 0.2 & 0.1 & 0.0 & 0.2 & 0.1 \\
\hline & $\mathrm{D}$ & 0.0 & 0.0 & 0.0 & 0.0 & 0.0 & 0.0 & 0.0 & 0.0 & 0.0 & 0.0 \\
\hline \multirow{4}{*}{10} & A & 0.2 & 0.3 & 0.2 & 0.1 & 0.2 & 0.3 & 0.2 & 0.5 & 0.5 & 0.6 \\
\hline & B & 0.7 & 0.6 & 0.5 & 0.6 & 0.7 & 0.6 & 0.7 & 0.4 & 0.4 & 0.3 \\
\hline & $\mathrm{C}$ & 0.1 & 0.1 & 0.3 & 0.3 & 0.1 & 0.1 & 0.1 & 0.1 & 0.1 & 0.1 \\
\hline & $\mathrm{D}$ & 0.0 & 0.0 & 0.0 & 0.0 & 0.0 & 0.0 & 0.0 & 0.0 & 0.0 & 0.0 \\
\hline \multirow{4}{*}{11} & A & 0.1 & 0.1 & 0.2 & 0.1 & 0.1 & 0.1 & 0.2 & 0.6 & 0.5 & 0.6 \\
\hline & B & 0.6 & 0.7 & 0.5 & 0.6 & 0.6 & 0.7 & 0.7 & 0.3 & 0.4 & 0.4 \\
\hline & $\mathrm{C}$ & 0.3 & 0.2 & 0.3 & 0.3 & 0.3 & 0.2 & 0.1 & 0.1 & 0.1 & 0.0 \\
\hline & $\mathrm{D}$ & 0.0 & 0.0 & 0.0 & 0.0 & 0.0 & 0.0 & 0.0 & 0.0 & 0.0 & 0.0 \\
\hline \multirow{4}{*}{12} & $\mathrm{~A}$ & 0.2 & 0.3 & 0.2 & 0.2 & 0.3 & 0.2 & 0.2 & 0.6 & 0.5 & 0.6 \\
\hline & B & 0.7 & 0.6 & 0.7 & 0.6 & 0.7 & 0.8 & 0.8 & 0.3 & 0.4 & 0.3 \\
\hline & $\mathrm{C}$ & 0.1 & 0.1 & 0.1 & 0.2 & 0.0 & 0.0 & 0.0 & 0.1 & 0.1 & 0.1 \\
\hline & $\mathrm{D}$ & 0.0 & 0.0 & 0.0 & 0.0 & 0.0 & 0.0 & 0.0 & 0.0 & 0.0 & 0.0 \\
\hline
\end{tabular}

Note: A: excellent, B: good, C: average, and D: poor.

Combine the membership degree of the 2nd-class indicators with their weight; then get the membership degree of the 1st-class indicators, as shown in Table 9.

Step 4. Calculate the agility membership degree of node enterprises combining the weight of the 1st-class indicators, as shown in Table 10.

Step 5. Calculate the result of comprehensive agility evaluation of agile supply chain network.

Combine the agility evaluation result of the node enterprises with the weight of the node enterprises; then get the result of comprehensive agility evaluation of agile supply chain network, as shown in Table 11.

\section{Conclusions}

In the agility evaluation of the agile supply chain network, we consider not only the weight of agility evaluation indicators but also the weight of node enterprises which reflects the effect of the structure of supply chain network on the agility. This is a complement to current evaluation methods of agility.

The paper firstly presents three concepts: node strength centrality, betweenness centrality, and network centrality, and it uses them to calculate the weight of node enterprises. Secondly, it uses AHP to calculate the weight of indicators which are used to evaluate agility of agile supply chain network. Thirdly, the paper uses Delphi method, Data Mining, and so forth to get initial agility evaluation matrix and then combines the matrix with the weight of indicators in order to get the agility membership degree of indicators. Lastly, it calculates the result of comprehensive agility evaluation of agile supply chain network on the basis of considering the weight of node enterprises.

The paper starts the research from the point of the network structure relationship of the individual node. In the future, the research can be carried out on effect which could be made by the characteristics of the whole network structure and their change on agility. For example, some characteristic indicators and their change can make influence on the agility of supply chain network, such as the largest functional network, clustering coefficient, and characteristic path length. The interaction mechanism between these characteristics and the agility of the supply chain network is worthy to be studied in order to improve the agility level of the supply chain network through adjusting the scale or the structure of the supply chain network. This is the work to be carried out for further research in this field.

\section{Conflict of Interests}

The authors declare that there is no conflict of interests regarding the publication of this paper.

\section{Acknowledgments}

The work of Nai-Ru Xu was supported in part by the Key Project of the Special Foundation for Young Scientists of Anhui Province of China under Grant no. 2013SQRW090ZD. The work of Jia-Bao Liu was supported by the Natural Science 
TABLE 9: The membership degree of the 1st-class indicators of node enterprises.

\begin{tabular}{|c|c|c|c|c|c|c|c|c|c|c|}
\hline \multirow{2}{*}{ Node } & \multirow{2}{*}{ Grade } & \multicolumn{9}{|c|}{ Indicator } \\
\hline & & $\mathrm{A} 1$ & $\mathrm{~A} 2$ & A3 & B1 & B2 & B3 & $\mathrm{C} 1$ & $\mathrm{C} 2$ & $\mathrm{C} 3$ \\
\hline \multirow{4}{*}{1} & A & 0.04 & 0.09 & 0.20 & - & - & - & - & - & - \\
\hline & B & 0.56 & 0.42 & 0.57 & - & - & - & - & - & - \\
\hline & $\mathrm{C}$ & 0.40 & 0.49 & 0.23 & - & - & - & - & - & - \\
\hline & $\mathrm{D}$ & 0.00 & 0.00 & 0.00 & - & - & - & - & - & - \\
\hline \multirow{4}{*}{2} & A & 0.09 & 0.09 & 0.17 & - & - & - & - & - & - \\
\hline & B & 0.63 & 0.50 & 0.60 & - & - & - & - & - & - \\
\hline & $\mathrm{C}$ & 0.28 & 0.41 & 0.23 & - & - & - & - & - & - \\
\hline & $\mathrm{D}$ & 0.00 & 0.00 & 0.00 & - & - & - & - & - & - \\
\hline \multirow{4}{*}{3} & A & 0.06 & 0.20 & 0.17 & - & - & - & - & - & - \\
\hline & B & 0.56 & 0.43 & 0.57 & - & - & - & - & - & - \\
\hline & $\mathrm{C}$ & 0.38 & 0.37 & 0.26 & - & - & - & - & - & - \\
\hline & $\mathrm{D}$ & 0.00 & 0.00 & 0.00 & - & - & - & - & - & - \\
\hline \multirow{4}{*}{4} & A & 0.09 & 0.12 & 0.17 & - & - & - & - & - & - \\
\hline & B & 0.62 & 0.63 & 0.60 & - & - & - & - & - & - \\
\hline & $\mathrm{C}$ & 0.29 & 0.25 & 0.23 & - & - & - & - & - & - \\
\hline & $\mathrm{D}$ & 0.00 & 0.00 & 0.00 & - & - & - & - & - & - \\
\hline \multirow{4}{*}{5} & $\mathrm{~A}$ & 0.07 & 0.04 & 0.17 & - & - & - & - & - & - \\
\hline & B & 0.63 & 0.60 & 0.60 & - & - & - & - & - & - \\
\hline & $\mathrm{C}$ & 0.30 & 0.36 & 0.23 & - & - & - & - & - & - \\
\hline & $\mathrm{D}$ & 0.00 & 0.00 & 0.00 & - & - & - & - & - & - \\
\hline \multirow{4}{*}{6} & A & - & - & - & 0.07 & 0.14 & 0.05 & - & - & - \\
\hline & B & - & - & - & 0.60 & 0.63 & 0.55 & - & - & - \\
\hline & C & - & - & - & 0.33 & 0.20 & 0.40 & - & - & - \\
\hline & $\mathrm{D}$ & - & - & - & 0.00 & 0.03 & 0.00 & - & - & - \\
\hline \multirow{4}{*}{7} & A & - & - & - & 0.07 & 0.07 & 0.05 & - & - & - \\
\hline & B & - & - & - & 0.70 & 0.60 & 0.55 & - & - & - \\
\hline & $\mathrm{C}$ & - & - & - & 0.23 & 0.30 & 0.40 & - & - & - \\
\hline & $\mathrm{D}$ & - & - & - & 0.00 & 0.03 & 0.00 & - & - & - \\
\hline \multirow{4}{*}{8} & A & - & - & - & 0.07 & 0.07 & 0.05 & - & - & - \\
\hline & B & - & - & - & 0.63 & 0.63 & 0.63 & - & - & - \\
\hline & C & - & - & - & 0.30 & 0.27 & 0.32 & - & - & - \\
\hline & $\mathrm{D}$ & - & - & - & 0.00 & 0.03 & 0.00 & - & - & - \\
\hline \multirow{4}{*}{9} & A & - & - & - & - & - & - & 0.18 & 0.17 & 0.57 \\
\hline & B & - & - & - & - & - & - & 0.58 & 0.67 & 0.33 \\
\hline & $\mathrm{C}$ & - & - & - & - & - & - & 0.24 & 0.16 & 0.10 \\
\hline & $\mathrm{D}$ & - & - & - & - & - & - & 0.00 & 0.00 & 0.00 \\
\hline \multirow{4}{*}{10} & A & - & - & - & - & - & - & 0.21 & 0.23 & 0.53 \\
\hline & B & - & - & - & - & - & - & 0.61 & 0.67 & 0.37 \\
\hline & $\mathrm{C}$ & - & - & - & - & - & - & 0.18 & 0.10 & 0.10 \\
\hline & $\mathrm{D}$ & - & - & - & - & - & - & 0.00 & 0.00 & 0.00 \\
\hline \multirow{4}{*}{11} & A & - & - & - & - & - & - & 0.12 & 0.14 & 0.56 \\
\hline & B & - & - & - & - & - & - & 0.61 & 0.67 & 0.37 \\
\hline & $\mathrm{C}$ & - & - & - & - & - & - & 0.27 & 0.19 & 0.07 \\
\hline & $\mathrm{D}$ & - & - & - & - & - & - & 0.00 & 0.00 & 0.00 \\
\hline \multirow{4}{*}{12} & A & - & - & - & - & - & - & 0.23 & 0.23 & 0.57 \\
\hline & B & - & - & - & - & - & - & 0.65 & 0.77 & 0.33 \\
\hline & $\mathrm{C}$ & - & - & - & - & - & - & 0.12 & 0.00 & 0.10 \\
\hline & $\mathrm{D}$ & - & - & - & - & - & - & 0.00 & 0.00 & 0.00 \\
\hline
\end{tabular}


TABLE 10: The agility membership degree of the node enterprises.

\begin{tabular}{|c|c|c|c|c|c|c|c|c|c|c|c|c|}
\hline \multirow{2}{*}{ Grade } & \multicolumn{12}{|c|}{ Node } \\
\hline & 1 & 2 & 3 & 4 & 5 & 6 & 7 & 8 & 9 & 10 & 11 & 12 \\
\hline A & 0.10 & 0.11 & 0.14 & 0.12 & 0.09 & 0.09 & 0.07 & 0.07 & 0.32 & 0.33 & 0.30 & 0.36 \\
\hline B & 0.52 & 0.58 & 0.52 & 0.62 & 0.61 & 0.60 & 0.62 & 0.63 & 0.51 & 0.54 & 0.53 & 0.56 \\
\hline C & 0.38 & 0.31 & 0.34 & 0.26 & 0.30 & 0.30 & 0.30 & 0.29 & 0.17 & 0.13 & 0.17 & 0.08 \\
\hline D & 0.00 & 0.00 & 0.00 & 0.00 & 0.00 & 0.01 & 0.01 & 0.01 & 0.00 & 0.00 & 0.00 & 0.00 \\
\hline
\end{tabular}

TABLE 11: The result of comprehensive agility evaluation of agile supply chain network.

\begin{tabular}{lcccc}
\hline Grade of agility & A & B & C & D \\
\hline Evaluation & 0.11 & 0.60 & 0.29 & 0.00 \\
\hline
\end{tabular}

Foundation of Anhui Province of China under Grant no. KJ2013B105, the Natural Science Foundation for the Higher Education Institutions of Anhui Province of China under Grant no. KJ2015A331. The authors would like to express sincere gratitude to the editor and the reviewers for their helpful comments and suggestions in improving the quality of this paper.

\section{References}

[1] S. I. Mari, Y. H. Lee, M. S. Memon, Y. S. Park, and M. Kim, "Adaptivity of complex network topologies for designing resilient supply chain networks," International Journal of Industrial Engineering, vol. 22, no. 1, pp. 102-116, 2015.

[2] T. Y. Choi, K. J. Dooley, and M. Rungtusanatham, "Supply networks and complex adaptive systems: control versus emergence," Journal of Operations Management, vol. 19, no. 3, pp. 351366, 2001.

[3] S. D. Pathak, J. M. Day, A. Nair, W. J. Sawaya, and M. M. Kristal, "Complexity and adaptivity in supply networks: building supply network theory using a complex adaptive systems perspective," Decision Sciences, vol. 38, no. 4, pp. 547-580, 2007.

[4] H. P. Thadakamalla, U. N. Raghavan, S. Kumara, and R. Albert, "Survivability of multiagent-based supply networks: a topological perspective," IEEE Intelligent Systems, vol. 19, no. 5, pp. 24-31, 2004.

[5] T. Tanizawa, G. Paul, R. Cohen, S. Havlin, and H. E. Stanley, "Optimization of network robustness to waves of targeted and random attacks," Physical Review E, vol. 71, no. 4, Article ID 047101, 2005.

[6] J. Zheng, "A modelling framework for the planning of strategic supply chain viewed from complex networks," Journal of Service Science and Management, vol. 2, no. 2, pp. 129-135, 2009.

[7] E. J. S. Hearnshaw and M. M. J. Wilson, "A complex network approach to supply chain network theory," International Journal of Operations \& Production Management, vol. 33, no. 4, pp. 442469, 2013.

[8] K. Zhao, A. Kumar, T. P. Harrison, and J. Yen, "Analyzing the resilience of complex supply network topologies against random and targeted disruptions," IEEE Systems Journal, vol. 5, no. 1, pp. 28-39, 2011.

[9] G. S. Metes, P. Bradish, and J. Gundry, Agile Networking: Competing through the Internet and Intranets, Prentice-Hall, Upper Saddle River, NJ, USA, 1998.
[10] H. T. Goranson, The Agile Virtual Enterprise: Cases, Metrics, Tools, Quorum Books, Westport, Conn, USA, 1999.

[11] N. C. Tsourveloudis and K. P. Valavanis, "On the measurement of enterprise agility," Journal of Intelligent and Robotic Systems, vol. 33, no. 3, pp. 329-342, 2002.

[12] C.-T. Lin, H. Chiu, and Y.-H. Tseng, "Agility evaluation using fuzzy logic," International Journal of Production Economics, vol. 101, no. 2, pp. 353-368, 2006.

[13] Y. Y. Yusuf, M. Sarhadi, and A. Gunasekaran, "Agile manufacturing: the drivers, concepts and attributes," International Journal of Production Economics, vol. 62, no. 1, pp. 33-43, 1999.

[14] V. Sambamurthy, A. Bharadwaj, and V. Grover, "Shaping agility through digital options: reconceptualizing the role of information technology in contemporary firms," MIS Quarterly, vol. 27, no. 2, pp. 237-264, 2003.

[15] H. Cho, M. Jung, and M. Kim, "Enabling technologies of agile manufacturing and its related activities in Korea," Computers and Industrial Engineering, vol. 30, no. 3, pp. 323-334, 1996.

[16] G. Fliedner and R. J. Vokurka, "Agility: competitive weapon of the 1990s and beyond?" Production and Inventory Management Journal, vol. 38, no. 3, pp. 19-24, 1997.

[17] H. S. Ismail and H. Sharifi, "A balanced approach to building agile supply chains," International Journal of Physical Distribution and Logistics Management, vol. 36, no. 6, pp. 431-444, 2006.

[18] R. Albert and A.-L. Barabási, "Statistical mechanics of complex networks," Reviews of Modern Physics, vol. 74, no. 1, pp. 47-97, 2002.

[19] Z. X. He, Fuzzy Mathematics and Its Application, Tianjin Science and Technology Press, Tianjin, China, 1985.

[20] S. Mishra, S. Sankar Mahapatra, and S. Datta, "Agility evaluation in fuzzy context: influence of decision-makers' risk bearing attitude," Benchmarking, vol. 21, no. 6, pp. 1084-1119, 2014.

[21] S. Mishra, S. Datta, and S. S. Mahapatra, "Grey-based and fuzzy TOPSIS decision-making approach for agility evaluation of mass customization systems," Benchmarking, vol. 20, no. 4, pp. 440-462, 2013.

[22] J. S. Dyer, "Remark on the analytic hierarchy process," Management Science, vol. 36, no. 3, pp. 249-258, 1990.

[23] M. G. David and C. H. Mary, "Understanding the role of logistics capabilities in achieving supply chain agility: a systematic literature review," Supply Chain Management, vol. 17, no. 4, pp. 438-453, 2012. 


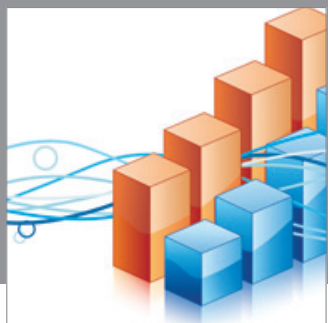

Advances in

Operations Research

mansans

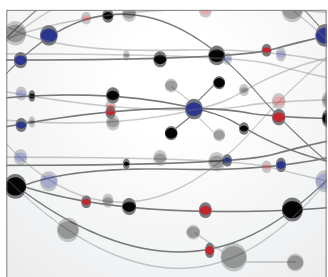

The Scientific World Journal
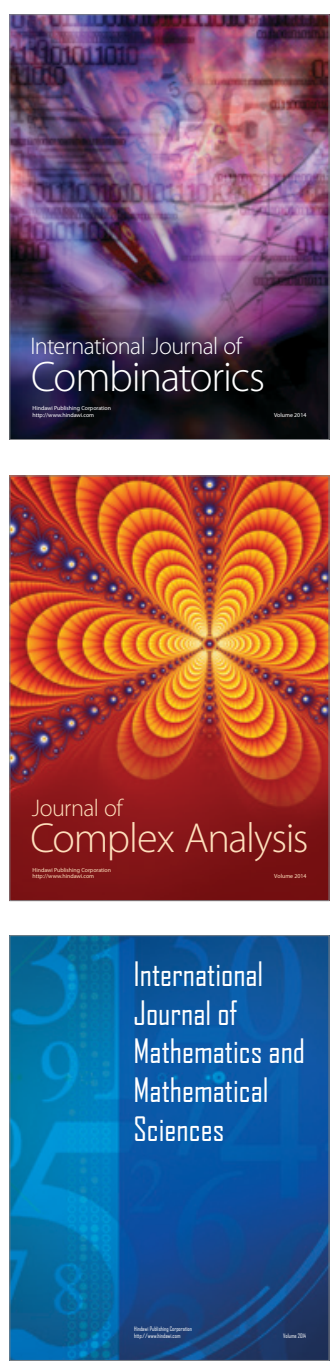
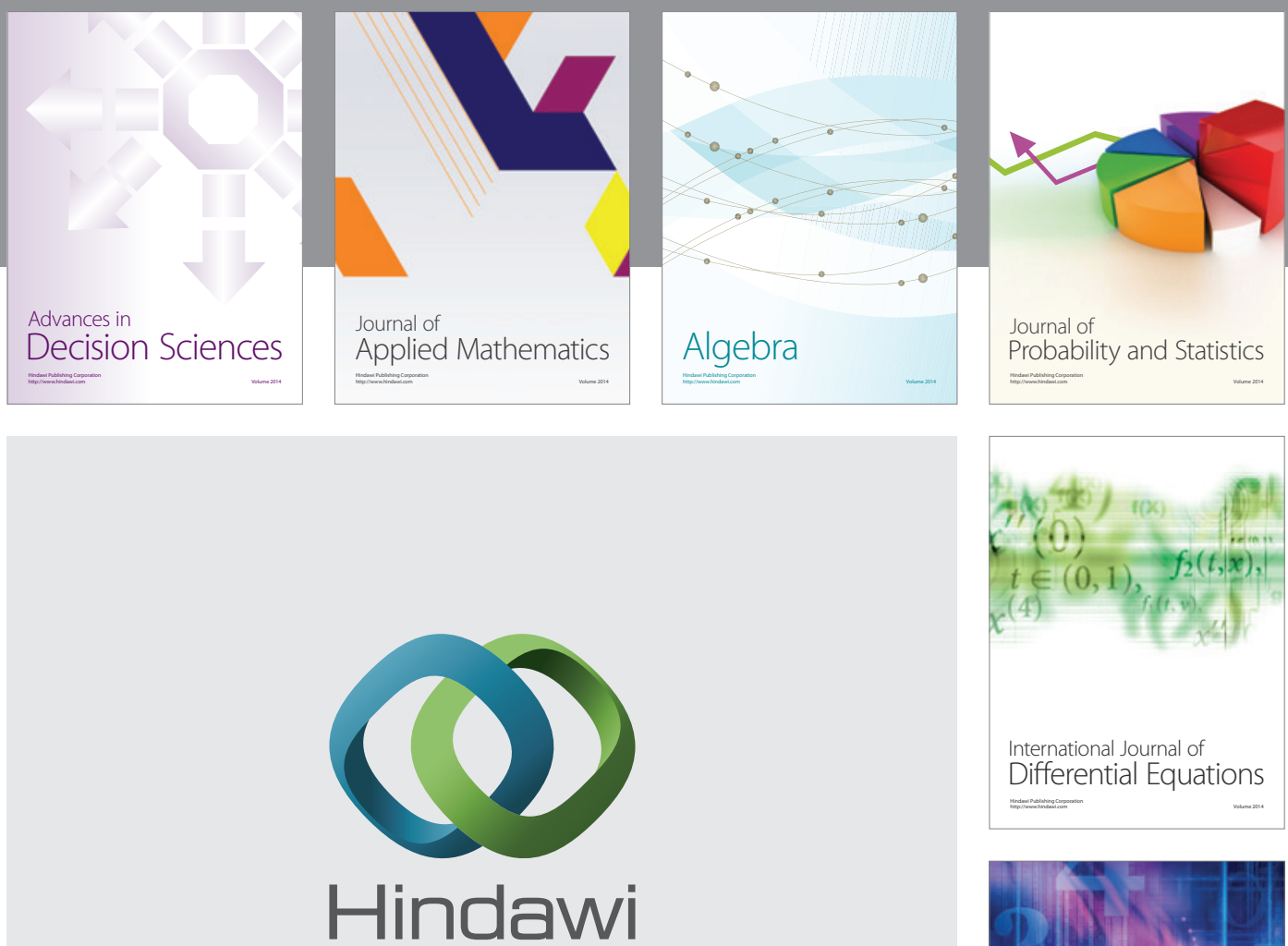

Submit your manuscripts at http://www.hindawi.com
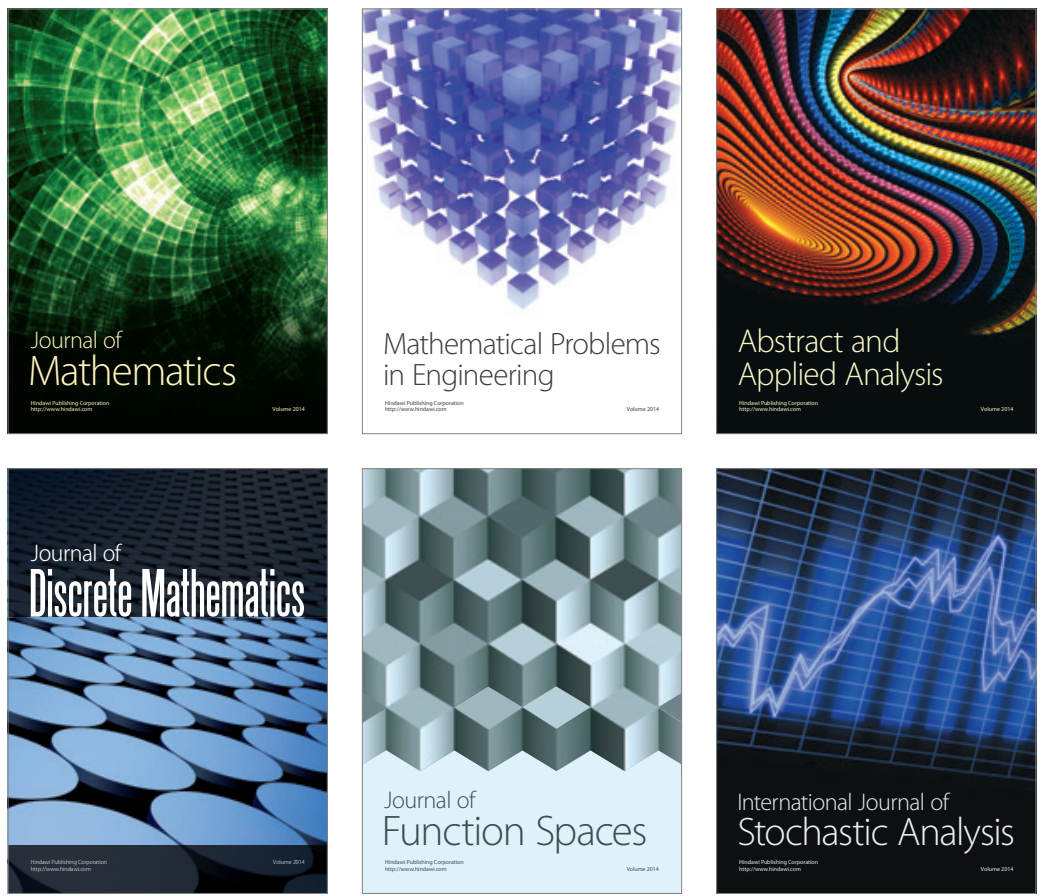

Journal of

Function Spaces

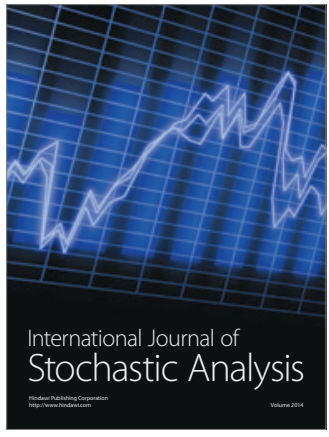

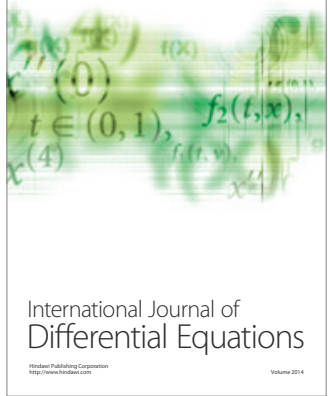
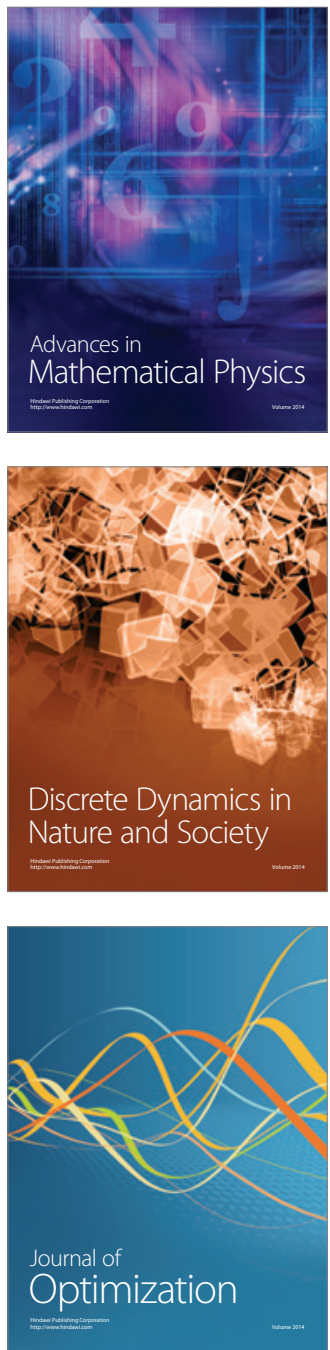